\title{
Hierarchically porous zirconia through precursor-directed large-scale synthesis
}

\author{
Gulaim A. Seisenbaeva $\mathbb{D}^{1} \cdot$ Oksana A. Dudarko $\mathbb{B}^{2} \cdot \operatorname{Vadim}$ G. Kessler $\mathbb{D}^{1}$
}

Received: 31 May 2018 / Accepted: 25 September 2018 / Published online: 2 October 2018

(c) The Author(s) 2018

\begin{abstract}
Two new precursors, produced by modification of zirconium t-butoxide with 1-dimethylamino-propanol-2 (HDMAP), solid $\mathrm{Zr}_{2}(\mathrm{DMAP})_{3}\left(\mathrm{O}^{\mathrm{t} B u}\right)_{5}(\mathbf{1})$, and liquid $\mathrm{Zr}_{2}(\mathrm{DMAP})_{4}\left(\mathrm{O}^{\mathrm{t}} \mathrm{Bu}\right)_{4}(\mathbf{2})$, were obtained by reaction of 1.5 and 2 equivalents of HDMAP, respectively, in toluene on $\mathrm{Zr}\left(\mathrm{O}^{\mathrm{t}} \mathrm{Bu}\right)_{4}$. The produced compounds were characterized by Fourier-transform infrared spectroscopy, ${ }^{1} \mathrm{H}$ and ${ }^{13} \mathrm{C}$ nuclear magnetic resonance (NMR), and thermogravimetric analysis (TGA) to estimate their stability and volatility. Action of traces of water in solvents or contact with humid air transforms $\mathbf{1}$ and $\mathbf{2}$ into less soluble crystalline $\mathrm{Zr}_{2}(\mathrm{DMAP})_{3}\left(\mathrm{O}^{\mathrm{t}} \mathrm{Bu}\right)_{4}(\mathrm{OH})(\mathbf{3})$. Molecular structures of compounds $\mathbf{1}$ and $\mathbf{3}$ were established using single-crystal $\mathrm{X}$-ray studies and for $\mathbf{2}$, they were elucidated by applying $2 \mathrm{D}{ }^{1} \mathrm{H}-{ }^{13} \mathrm{C}$-correlated NMR spectra. The crystals of 1 were subjected to hydrolysis via either storage in ambient atmosphere or immersion into boiling water and the resulting products were characterized by X-ray powder diffraction, TGA, scanning electron microscopy, and atomic force microscopy techniques. The product of hydrolysis in air, $\mathrm{ZrO}_{2}-1$, is essentially nonporous, while hydrolysis in boiling water results in $\mathrm{ZrO}_{2}-2$ with hierarchical macro-, meso-, and microporosity. Both materials are essentially X-ray amorphous with diffraction patterns appearing as oblique curves, resembling unresolved profiles of the monoclinic baddeleyite structure of $\mathrm{ZrO}_{2}$. Heat treatment at 200 and $400{ }^{\circ} \mathrm{C}$ does not affect essentially the morphology or porosity and leaves the phase composition unchanged, while that at $600{ }^{\circ} \mathrm{C}$ converts both samples into a tetragonal $\mathrm{ZrO}_{2}$ phase. The $\mathrm{ZrO}_{2}-2$ material is via this treatment losing microporosity and becoming macro-mesoporous with a well-defined pore size of about $3 \mathrm{~nm}$. Heat treatment at $900{ }^{\circ} \mathrm{C}$ results in collapse of pores and transformation into a well-defined monoclinic baddeleyite structure for both materials.
\end{abstract}

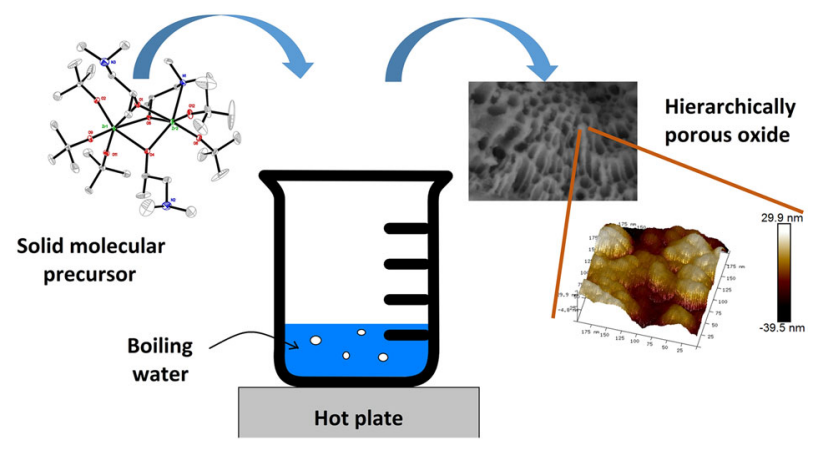

Vadim G. Kessler

vadim.kessler@slu.se

1 Department of Molecular Sciences, BioCenter, Swedish University of Agricultural Sciences, Box 7015, 75007
Uppsala, Sweden

2 Chuiko Institute of Surface Chemistry of National Academy of Sciences of Ukraine, 17, General Naumov Street, 03164 Kyiv, Ukraine 


\section{Highlights}

- Heteroleptic zirconium alkoxide-aminoalkoxide precursors were synthesized and characterized.

- Precursor hydrolysis in boiling water offered hierarchically macro-meso-microporous zirconia resulting from liganddriven reaction mechanisms discussed in detail.

- Heat treatment at $600^{\circ} \mathrm{C}$ results in disappearing of microporosity and transformation into a crystalline tetragonal $\mathrm{ZrO}_{2}$.

- Heating to $900{ }^{\circ} \mathrm{C}$ leads to collapse of pores and transformation into a monoclinic $\mathrm{ZrO}_{2}$.

Keywords Porous $\mathrm{ZrO}_{2} \cdot$ Precursor-directed synthesis $\cdot$ Aminoalkoxide ligand $\cdot$ Rapid hydrothermal synthesis $\cdot$ Thermal evolution of porosity

\section{Introduction}

Porous zirconium oxide finds a broad spectrum of applications due to its attractive characteristics such as chemical and thermal stability [1] and pronounced affinity to several classes of biomolecules. Among possible uses of such materials are adsorbents for extraction of proteins [2] and nucleic acids [3] as well as fillers for columns for chromatographic separations [4]. An important application of porous zirconia is in coatings constituting functional layers of tubular membranes for cleaning of water and raw oils by filtration [4]. Also, thermal barrier coatings have attracted considerable attention and air plasma spraying was found to be instrumental in their preparation $[5,6]$.

The most attractive approach to preparation of porous metal oxides is the sol-gel technology since the discovery of the process for production of mesoporous $\mathrm{Al}_{2} \mathrm{O}_{3}$ from aluminum isopropoxide by Tischenko in early 1900s [7]. The possibility to achieve formation of hierarchical porosity, combining macro-, meso-, and microporosity is highly attractive for the applications in question [8]. This is however a recognized challenge for zirconia that is often obtained as materials with closed mesoporosity and especially producing reproducible microporosity in both coatings and bulk material is considered difficult [9].

Behind this challenge lies the very nature of sol-gel mechanism for formation of metal oxides that is based on the so-called micelle templated by self-assembly of ligands (MTSAL) phenomenon [10]. The metal oxides are nucleating in the hydrolytic process in the form of polyoxometallate-like species with well ordered, in some cases even appreciably crystalline cores with the size generally $3-5 \mathrm{~nm}$, covered by residual organic ligands [11-13]. The subsequent removal of ligands is associated with aggregation of the initially produced nuclei and creation of interparticle mesoporosity that often becomes closed due to coalescence of the particles on the surface of aggregates resulting in a dense outer layer [14]. To overcome this difficulty, a use of phase inversion and template synthesis has been proposed [15]. Another successful approach rendering uniformly porous zirconia has been developed by Pinna et al., exploiting high-temperature hydrothermal synthesis [16], where the initially solvothermally generated uniform $\mathrm{ZrO}_{2}$ particles self-assembled into dense hexagonal packing-derived mesocrystals.

In order to avoid the use of surfactants and extreme conditions, we have earlier proposed to apply an approach that we designated as rapid hydrothermal synthesis when a solid alkoxide precursor was immersed into boiling water to achieve a rapid removal of all organics as volatiles [14]. This approach was demonstrated to be efficient in the creation of $\mathrm{ZrO}_{2}$ materials with a large surface area and open mesoporosity that displayed attractive characteristics as adsorbents for water cleaning from heavy metal pollutants [17]. It has been demonstrated earlier that microporosity could successfully be incorporated into materials if alkoxide precursors applied were carrying not simply chelating, but chelating-and-bridging ligands such as aminoalcohols [18].

The interest in zirconium aminoalkoxide-substituted precursors emerged originally in view of their potential application in the metal-organic chemical vapour deposition technique. In a comprehensive study reported by O'Brien and Jones [19], several amino alcohol ligands such as 2-dimethylamino-ethanol (HDMAE), 1-dimethylamino2-propanol (HDMAP), and 1,1-bis-dimethylamino-propanol-2 (HBDMAP) were used for modification of either zirconium isopropoxide or zirconium tert-butoxide. Three individual compounds were isolated, namely $\mathrm{Zr}_{2}\left(\mathrm{OPr}^{\mathrm{i}}\right)_{6}$ $(\text { DMAP })_{2}, \mathrm{Zr}_{2}\left(\mathrm{OPr}^{\mathrm{i}}\right)_{6}(\mathrm{BDMAP})_{2}$, and $\mathrm{Zr}_{2}\left(\mathrm{OBu}^{\mathrm{t}}\right)_{3}(\mathrm{BDMAP})$ ${ }_{4}(\mathrm{OH})$, where DMAP and BDMAP stay for the anionic forms of the above-mentioned alcohols. The structures of the obtained heteroleptic derivatives revealed them to be dimeric, not monomeric as it was expected by the authors. The volatility and thermal stability turned limited, which partly removed attention from this class of compounds. The utility of heteroleptic aminoalkoxide precursors was underlined in ref. [18], where it has been demonstrated that chelating-and-bridging ligands were capable to offer access to microporosity for metal oxides.

Looking for new precursors of porous materials, we turned our attention to t-butoxides. This bulky alkoxide ligand was on one hand opening for extremely high hydrolytic reactivity via lowering of the coordination 
number of the central atoms. On the other hand, it is a derivative of an amphiphilic alcohol, which may offer additional advantages via formation of self-assembled vesicles. The latter are in aqueous medium self-opening via osmotic effects and providing macroporosity as we could observe in the synthesis of $\mathrm{TiO}_{2}$ from precursors bearing amphiphilic ligands [20].

In the present study, we were able to demonstrate that aminoalcohols when entering the structures of zirconium butoxide complexes are acting as chelating-and-bridging ligands. This inspired us to follow their transformations on hydrolysis in both humid air and in boiling water that in fact were able to deliver materials combining micro- and mesoand also quite attractive macroporosity.

\section{Experimental}

All operations with precursor chemicals were carried out in dry nitrogen atmosphere using a Schlenk line or glove box. The produced oxides were treated under ambient conditions. All chemicals were purchased from Sigma Aldrich. Zirconium t-butoxide, $\mathrm{Zr}\left(\mathrm{O}^{\mathrm{t}} \mathrm{Bu}\right)_{4}$, CAS No. 2081-12-1 was used as received without further purification. Toluene, $\mathrm{C}_{7} \mathrm{H}_{8}$, CAS No 108-88-3 was purified by distillation over lithium aluminum hydride, $\mathrm{LiAlH}_{4}$ (CAS No. 16853-85-3). An aliquot of 1-dimethylamino-2-propanol, HDMAP, $\mathrm{CH}_{3} \mathrm{CH}(\mathrm{OH}) \mathrm{CH}_{2} \mathrm{~N}\left(\mathrm{CH}_{3}\right)_{2}$, CAS No. 108-16-7, was stored for at least $24 \mathrm{~h}$ before use over $\mathrm{NaA} 4 \AA$ zeolite, preliminarily heat treated in $4 \mathrm{~h}$ at $400^{\circ} \mathrm{C}$.

\subsection{Synthesis and isolation}

$\mathrm{Zr}_{2}(\mathrm{DMAP})_{3}\left(\mathrm{O}^{\mathrm{t}} \mathrm{Bu}\right)_{5}(\mathbf{1}) . \mathrm{Zr}\left(\mathrm{O}^{\mathrm{t}} \mathrm{Bu}\right)_{4}(10.0 \mathrm{~g}, 26 \mathrm{mmol})$ was dissolved in $20 \mathrm{ml}$ of toluene and HDMAP $(4.0 \mathrm{~g}, 39 \mathrm{mmol})$ was quickly added to the solution by a syringe on vigorous stirring. The stirring continued in $1 \mathrm{~h}$ until the mixture cooled down and then toluene was evaporated in vacuum $\left(10^{-2} \mathrm{mmHg}\right)$ and collected in a trap cooled by liquid nitrogen. The residual pale yellowish viscous product crystallized within a week, leaving colorless transparent crystals of $\mathbf{1}$. The composition and structure of the product were established by X-ray single-crystal study. The identity of the bulk with the sample was confirmed by unit cell determinations for six randomly chosen crystals. Nuclear magnetic resonance (NMR) ${ }^{1} \mathrm{H}$ : sextet $3.76,3 \mathrm{H}, \mathrm{O}-\mathrm{CH}$, singlet $2.30,18 \mathrm{H}, \mathrm{N}-\mathrm{CH} 3$, doublet $2.25,6 \mathrm{H}, \mathrm{CH} 2$, singlet $1.25,45 \mathrm{H}, \mathrm{C}-\mathrm{CH} 3$, doublet $1.18,9 \mathrm{H}, \mathrm{O}-\mathrm{C}-\mathrm{CH}$. Fouriertransform infrared spectroscopy (FTIR): 2968s, 2924s, 2866m, 2764w, 1605w, 1496w, 1465m, 1458m, 1380m, $1355 \mathrm{~s}, 1225 \mathrm{~s}, 1192 \mathrm{vs}, 1140 \mathrm{~m}, 1089 \mathrm{~m}, 1005 \mathrm{vs}, 998 \mathrm{vs}$, 948w, 931w, 871w, 838w, 779m, 728s, 695w, 674vw, $577 \mathrm{~m}, 531 \mathrm{~s}, 484 \mathrm{~m}, 464 \mathrm{w}, 419 \mathrm{~m}$.
$\mathrm{Zr}_{2}(\mathrm{DMAP})_{4}\left(\mathrm{O}^{\mathrm{t}} \mathrm{Bu}\right)_{4}$ (2). $\mathrm{Zr}\left(\mathrm{O}^{\mathrm{t}} \mathrm{Bu}\right)_{4}(10.0 \mathrm{~g}, 26 \mathrm{mmol})$ was dissolved in $20 \mathrm{ml}$ of toluene and HDMAP $(6.0 \mathrm{~g}, 52$ mmol) was quickly added to the solution on vigorous stirring. After an hour of further stirring, toluene was evaporated in vacuum $\left(10^{-2} \mathrm{mmHg}\right)$ and collected in a trap cooled by liquid nitrogen. The residual yellowish liquid did not show any sign of crystallization on anhydrous conditions. NMR ${ }^{1} \mathrm{H}$ : sextet $3.76,4 \mathrm{H}, \mathrm{O}-\mathrm{CH}$, singlet $2.30,24 \mathrm{H}$, $\mathrm{N}-\mathrm{CH} 3$, doublets 2.25 and $2.18,4 \mathrm{H}$ and $4 \mathrm{H}, \mathrm{CH} 2$, singlet $1.25,36 \mathrm{H}, \mathrm{C}-\mathrm{CH} 3$, doublet $1.18,12 \mathrm{H}, \mathrm{O}-\mathrm{C}-\mathrm{CH} 3$. FTIR: $3027 \mathrm{w}, 3000 \mathrm{vs}, 2967 \mathrm{~s}, 2924 \mathrm{~s}, 2832 \mathrm{~m}, 2767 \mathrm{sh}, 1605 \mathrm{w}$, $1496 \mathrm{w}, 1465 \mathrm{~m}, 1457 \mathrm{~s}, 1379 \mathrm{~m}, 1355 \mathrm{~s}, 1275 \mathrm{vw}, 1264 \mathrm{vw}$, $1224 \mathrm{~m}, 1192 \mathrm{~s}, 1140 \mathrm{~s}, 1089 \mathrm{~m}, 1011 \mathrm{vs}, 998 \mathrm{~s}, 968 \mathrm{~m}, 951 \mathrm{~m}$, $874 \mathrm{w}, 856 \mathrm{vw}, 838 \mathrm{~m}, 779 \mathrm{~m}, 729 \mathrm{~s}, 695 \mathrm{~m}, 586 \mathrm{~m}, 577 \mathrm{~m}$, 532s, 483w, 464w, 427m.

$\mathrm{Zr}_{2}(\mathrm{DMAP})_{3}\left(\mathrm{O}^{\mathrm{t}} \mathrm{Bu}\right)_{4}(\mathrm{OH})(\mathbf{3})$. This compound was isolated as single crystals from a sample of $\mathbf{2}$ exposed to moist air and from a sample of solution of $\mathbf{1}$ in toluene on prolonged storage. No attempts were made for quantitative isolation of $\mathbf{3}$. Its composition and structure were confirmed solely by single-crystal studies.

\subsection{Characterization}

The NMR investigation of the samples was carried out with Bruker Avance 600 Smart Probe spectrometer. Thermogravimetric analysis studies were made using Perkin-Elmer Pyris 1 instrument. FTIR investigation was performed with a Perkin-Elmer Spectrum 100 instrument. Mass-spectrometric studies were carried out on a Q-TOF spectrophotometer (at the A.N. Nesmeyanov Institute of Organoelement Compounds, Russian Academy of Sciences, Moscow, Russian Federation) in electrospray ionization mode using acetonitrile and acetonitrile-toluene solutions. $\mathrm{X}$-ray single-crystal and powder diffraction studies were performed with a Bruker SMART Apex-II diffractometer operating with $\mathrm{MoK} \alpha$ radiation. Atomic force microscopy (AFM) studies were carried out with Bruker Fastscan Bio instrument. Scanning electron microscopy (SEM) images were recorded with Hitachi TM-1000- $\mu$-DeX electron microscope supplied with an energy dispersion spectroscopy detector. Nitrogen adsorption-desorption tests were made using Sorptometer KELVIN 1042 of COSTECH Instruments.

\subsection{Crystallography}

The data collection were carried out at room temperature on crystals sealed in thin-walled glass capillaries. The data were integrated and adsorption-corrected using Bruker Apex-II software. The details of data collection and refinement are presented below. Both structures were solved by direct methods and the metal atom coordinates were 
extracted from the original solutions, while the other nonhydrogen atoms were located in subsequent Fourier syntheses. All non-hydrogen atoms were refined first in isotropic and then-in anisotropic approximation. Hydrogen atoms, except for the hydroxide hydrogen in the structure of $\mathbf{3}$, were added via geometric calculations and included into the final refinement in isotropic approximation. Full details of solution and refinement can be obtained free-of-charge from the Cambridge Crystallographic Data Centre at www.ccdc. cam.ac.uk citing the deposition numbers 1845862 and 1845863 for 1 and 3 , respectively.

1: $\mathrm{C}_{36} \mathrm{H}_{84} \mathrm{~N}_{4} \mathrm{O}_{8} \mathrm{Zr}_{2}, \mathrm{M}=883.51 \mathrm{Da}$, monoclinic space group $\mathrm{P} 2(1) / c, a=11.790(5), b=26.135(10), c=13.526$ (5) $\AA, \beta=90.637(5)^{\circ}, V=4168(3) \AA^{3}, Z=4$, and $D_{\text {calc }}=$ $1.272 \mathrm{~g} / \mathrm{cm}^{3}$. Totally, 8431 independent reflections (7304 observed with $I>2$ sigma(I)) were collected until 2Theta $=$ $50.50^{\circ}$. The refinement converged with least-square parameters $\mathrm{R} 1=0.0436$, $\mathrm{wR} 2=0.1122$, and $\mathrm{GOOF}=1.026$ for the observed and $\mathrm{R} 1=0.0505, \mathrm{wR} 2=0.1168$, and $\mathrm{GOOF}=1.078$ for all reflections.

3: $\mathrm{C}_{31} \mathrm{H}_{73} \mathrm{~N}_{3} \mathrm{O}_{8} \mathrm{Zr}_{2}, \mathrm{M}=798.36 \mathrm{Da}$, monoclinic space group $\mathrm{P} 2(1) / \mathrm{n}, \quad a=19.4029(9), \quad b=10.5627(5), \quad c=$ 23.4728(11) $\AA, \beta=104.557(2)^{\circ}, V=4656.2(4) \AA^{3}, Z=4$, and $D_{\text {calc }}=1.260 \mathrm{~g} / \mathrm{cm}^{3}$. Totally, 7322 independent reflections (6804 observed with $I>2$ sigma(I)) were collected until 2 Theta $=50.05^{\circ}$. The refinement converged with leastsquare parameters $\mathrm{R} 1=0.0267, \mathrm{wR} 2=0.0615$, and GOOF
$=0.934$ for the observed and $\mathrm{R} 1=0.0293, \mathrm{wR} 2=0.0627$, and $\mathrm{GOOF}=0.953$ for all reflections.

\subsection{Hydrolytic and thermal treatment}

Portions of ca. $2 \mathrm{~g}$ of $\mathbf{1}$ were either left in open air in $72 \mathrm{~h}$, producing the $\mathrm{ZrO}_{2}-1$ sample as a pale sticky powder or were immersed into $50 \mathrm{ml}$ of boiling water. The white sediment formed in the latter case was separated by decantation and dried overnight in air, leaving a dry whitecolored powdery material designated as $\mathrm{ZrO}_{2}-2$. The samples of both $\mathrm{ZrO}_{2}-1$ and $\mathrm{ZrO}_{2}-2$ were then subjected to heat treatment in air for $1 \mathrm{~h}$ at the temperatures 200,400,600, and $900{ }^{\circ} \mathrm{C}$.

\section{Results and discussion}

Investigation of the reaction products at different modification ratios permitted to demonstrate that, scanning through the composition range, the first crystalline product that could be isolated was corresponding unexpectedly not to $\mathrm{Zr}: \mathrm{L}=1: 1$, but to $1: 1.5$ ratio and resulted in formation of the compound $\mathrm{Zr}_{2}(\mathrm{DMAP})_{3}\left(\mathrm{O}^{t} \mathrm{Bu}\right)_{5}(\mathbf{1})$. The structure of 1 (see Fig. 1) is built up of an asymmetric dimeric core, where both $\mathrm{Zr}$ atoms are hexa-coordinated.

Fig. 1 Molecular structure of $\mathrm{Zr}_{2}$ $(\mathrm{DMAP})_{3}\left(\mathrm{O}^{\mathrm{t}} \mathrm{Bu}\right)_{5}(\mathbf{1})$

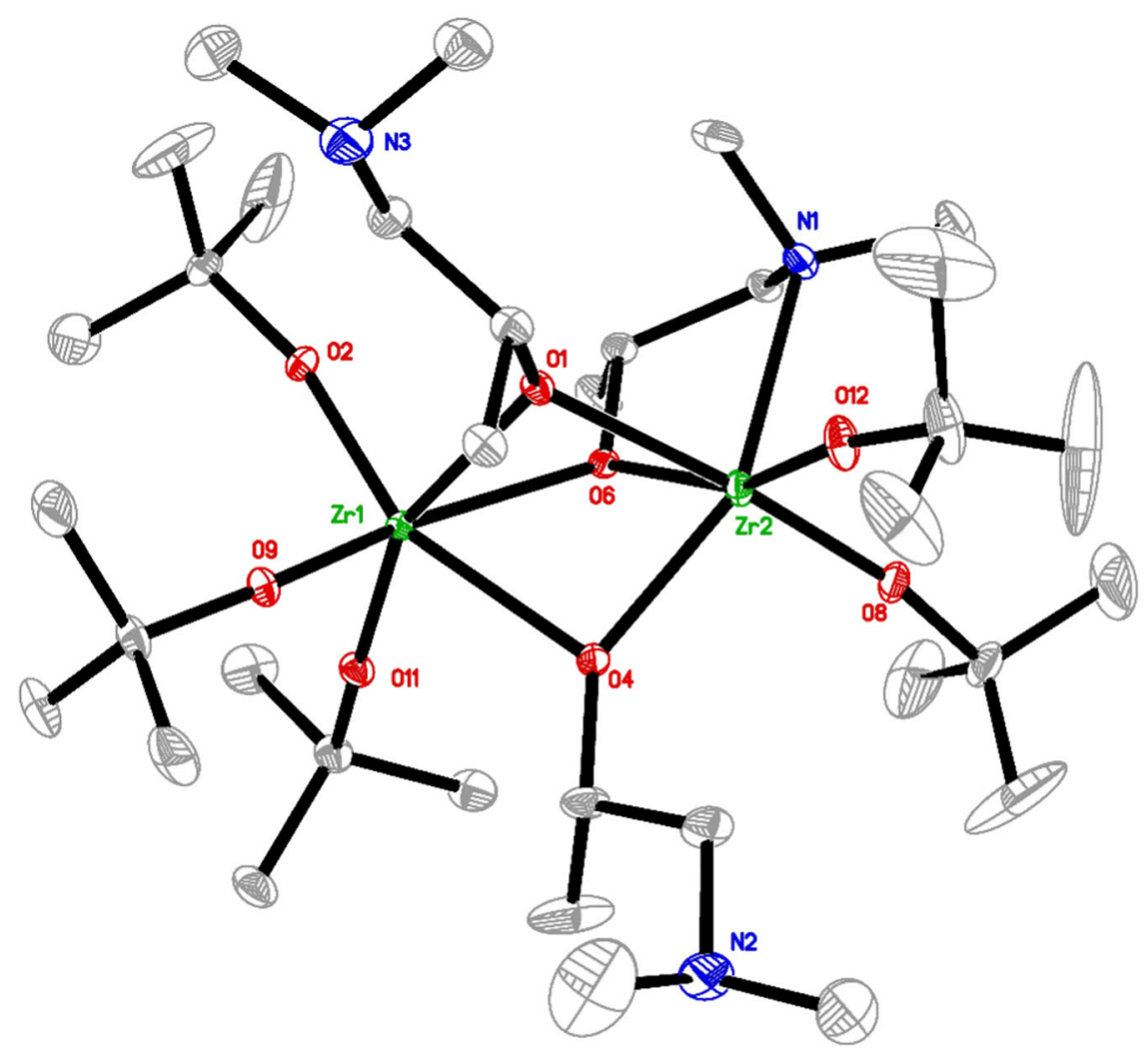


Fig. 2 The COSY ${ }^{1} \mathrm{H}-{ }^{13} \mathrm{C}$ correlation NMR spectrum of the $\mathrm{Zr}_{2}\left(\mathrm{O}^{\mathrm{t}} \mathrm{Bu}\right)_{4}(\mathrm{DMAP})_{4}$ (2). The signals originating from the solvent, toluene-d8, are indicated by the asterisk. Attribution of the signals: 1sextet 3.76, 4H, O- $\mathrm{CH}, 2-$ singlet $2.30,24 \mathrm{H}, \mathrm{N}-\mathrm{CH} 3,3$ doublets 2.25 and $2.18,4 \mathrm{H}$ and $4 \mathrm{H}, \mathrm{CH} 2,4$-singlet $1.25,36 \mathrm{H}$, $\mathrm{C}-\mathrm{CH} 3, \mathbf{5}$-doublet $1.18,12 \mathrm{H}$, $\mathrm{O}-\mathrm{C}-\mathrm{CH}$.

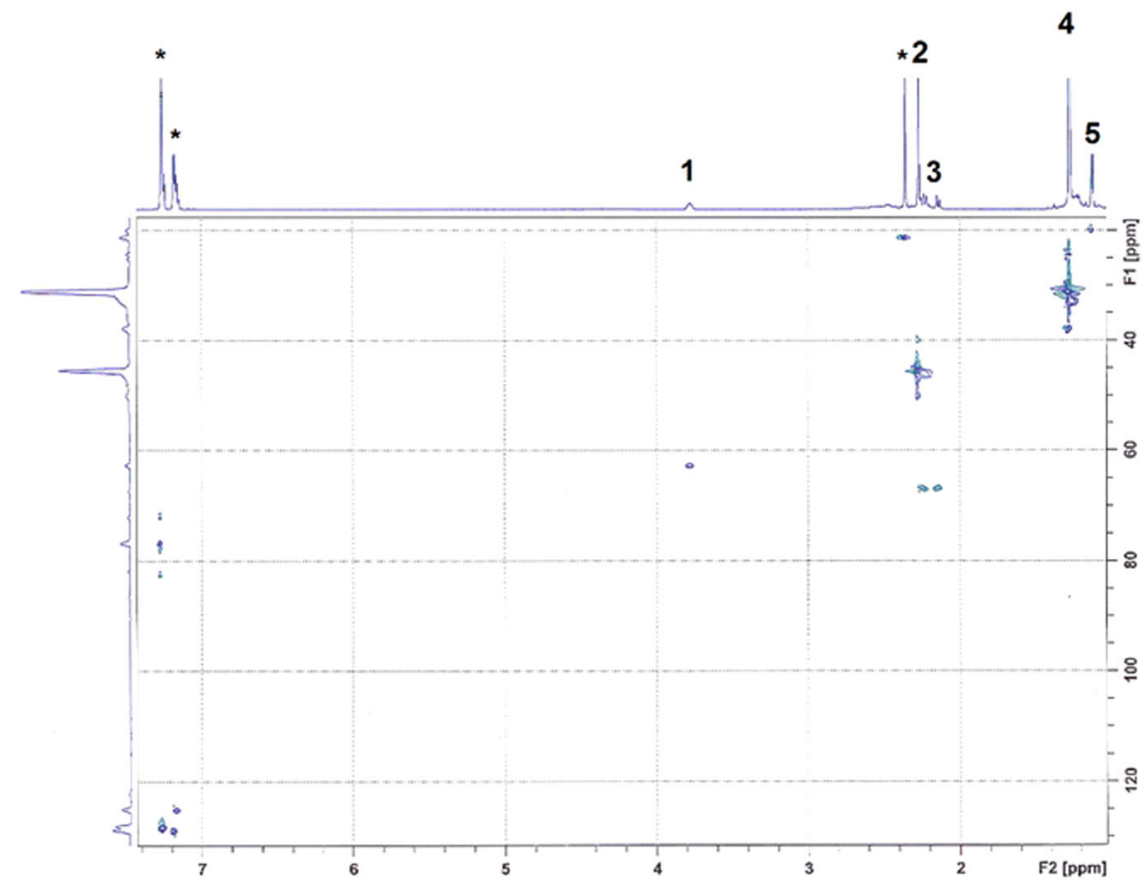

The coordination sphere of $\mathrm{Zr}(1)$ atom is composed of three $\mathrm{O}$-atoms of terminal $\mathrm{O}^{t} \mathrm{Bu}$-groups and three $\mathrm{O}$-atoms of the bridging DMAP functions. Two of them are solely bridging ones, while the third is chelating and bridging with its nitrogen atom involved into the coordination sphere of $\mathrm{Zr}(2)$ atom that is completed by three O-atoms of the bridging DMAP ligands and two O-atoms of the terminal $\mathrm{O}^{t} \mathrm{Bu}$-groups. It is interesting to note that in solution at room temperature, only one collection of DMAP signals is observed, indicating quick exchange in the functionality between the bridging functional ligands. The isolation of 1 with $\mathrm{M}: \mathrm{L}=2: 3$ ratio supposedly is caused by the bulky nature of the tert-butyl group, as we could also observe earlier considerable differences in compositions of stable alkoxide beta-diketonate complexes between isopropoxide and tert-butoxide derivatives [21].

The complex isolated at $\mathrm{Zr}: \mathrm{L}=1: 2$ ratio, $\mathrm{Zr}_{2}(\mathrm{DMAP})_{4}$ $\left(\mathrm{O}^{t} \mathrm{Bu}\right)_{4}(2)$, remained liquid at room temperature and formed a glassy solid on cooling. Its FTIR spectrum was not fully conclusive. The nature of the obtained product was thus revealed by the electrospray mass spectrometry, where the intense high-mass ions in the spectrum featured compositions $\mathrm{Zr}_{2}\left(\mathrm{O}^{t} \mathrm{Bu}\right)_{4}(\mathrm{DMAP})_{4}{ }^{-}$or $[\mathrm{M}]$, i.e., the molecular ion, at $m / z=880$ and $\mathrm{Zr}_{2}\left(\mathrm{O}^{\mathrm{t}} \mathrm{Bu}\right)_{4}(\mathrm{DMAP})_{3}(\mathrm{OH})^{-}$or $[\mathrm{M}-$ $\left.\mathrm{CH}_{2}=\mathrm{C}-\mathrm{NMe}_{2}, \mathrm{M}^{*}\right]$ at $m / z=795$. The NMR spectra were registered in toluene- $\mathrm{d} 8$, and the signals originating from the solvent are marked with an asterisk (see Fig. 2 for the COSY ${ }^{1} \mathrm{H}-{ }^{13} \mathrm{C}$ correlation spectrum). Clear splitting was observed for two different $\mathrm{CH} 2$-fragment signals, indicating the presence of two different types of aminoalkoxide ligands. The spectra were in excellent correlation with the proposed composition according to the integration ratios between the signals corresponding to the tert-butoxide and DMAP ligands. The presence of two different signals for DMAP CH2-fragments is supposedly due to one being chelating and bridging as in the $\mathrm{Zr}_{2}\left(\mathrm{O}^{t} \mathrm{Bu}\right) 5$ (DMAP) 3 compound, and another-terminal one with apparently less quick exchange between those in $\mathbf{2}$.

Microhydrolysis of both species results in formation with the minor yield of the crystalline product $\mathrm{Zr}_{2}(\mathrm{DMAP})_{3}$ $\left(\mathrm{O}^{t} \mathrm{Bu}\right)_{4}(\mathrm{OH})$ (3). The structure of the molecule of $\mathbf{3}$ resembles that of $\mathbf{1}$ and is forming from it apparently by the loss of one $\mathrm{O}^{t} \mathrm{Bu}$-group, while $\mathbf{2}$ converting into $\mathbf{3}$ is losing apparently one DMAP ligand. The structure of $\mathbf{3}$ (Fig. 3) is also featuring an asymmetric dimeric core.

The difference between the $\mathrm{Zr}$ atoms becomes, however, much more pronounced: the $\operatorname{Zr}(1)$ remains surrounded by three oxygen atoms of the terminal alkoxide groups and three bridging oxygen atoms, two of which belong to DMAP ligands and one- - a bridging hydroxide. The coordination of the $\operatorname{Zr}(2)$ atom can be considered to be resulting from chelation with three DMAP ligands-two of them are providing their bridging $\mathrm{O}$-atoms and amino groups, while the third has a terminal oxygen function, while its dimethylamino group is connected, being a hydrogen bond to the bridging hydroxide group. The structure of the molecule of $\mathbf{3}$ resembles that of $\mathbf{1}$ and is forming from it apparently by the loss of one $\mathrm{O}^{t} \mathrm{Bu}$-group, while $\mathbf{2}$ converting into $\mathbf{3}$ is losing apparently one DMAP ligand. This indicates that hydrolysis is potentially not removing all the aminoalkoxide 
Fig. 3 Molecular structure of $\mathrm{Zr}_{2}$ $(\mathrm{DMAP})_{3}\left(\mathrm{O}^{\mathrm{t}} \mathrm{Bu}\right)_{4}(\mathrm{OH})(\mathbf{3})$
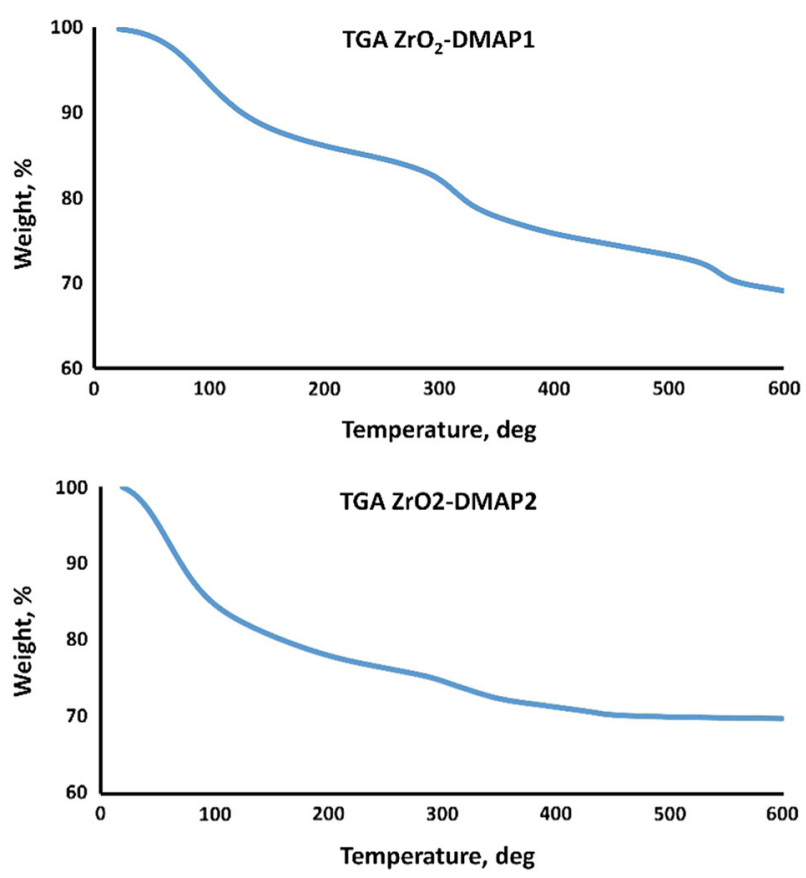

Fig. 4 TGA of $\mathrm{ZrO}_{2}-\mathrm{DMAP} 1$ (above) and $\mathrm{ZrO}_{2}-\mathrm{DMAP} 2$ (below)

groups completely, but preserving them inside the oxometallate nuclei in chelated-and-bridging form, opening for creation of microporosity.

Encouraged by the apparently favorable chemistry of precursors, we selected to evaluate two alternative transformation pathways - the hydrolysis in open air and the rapid hydrothermal synthesis via immersion of the solid precursor 1 into boiling water. The two products designated as $\mathrm{ZrO}_{2}-1$ and $\mathrm{ZrO}_{2}-2$ for the two approaches, respectively, display distinctly different composition and thermal behavior. The $\mathrm{ZrO}_{2}-1$ (see Fig. 4, above) is less rich in water, about $15 \%$, evaporating at about $100^{\circ} \mathrm{C}$ and contains quite much relatively strongly bound amino alcohol, about $10 \%$, removed at $320^{\circ} \mathrm{C}$ with pronounced carbonization. The residual carbon $5-6 \%$ is finally mostly burnt out at $540{ }^{\circ} \mathrm{C}$. The $\mathrm{ZrO}_{2}-2$ (see Fig. 4, below) is mostly containing water that is evaporated quite easily below $100^{\circ} \mathrm{C}$, about $23 \%$. The content of chemically bound DMAP removed also at $320{ }^{\circ} \mathrm{C}$ is almost twice lower, $5-6 \%$. The same is observed for the residual carbon that averages only ca. $1.5 \%$ in this material, and is removed by oxidation already below $500^{\circ}$ C. Morphology and porosity of the two samples (see Fig. 5), determined after drying in vacuum at $120^{\circ} \mathrm{C}$ for $4 \mathrm{~h}$, differ also quite pronouncedly. The role of boiling water lies in removal of the organic ligands by evaporation. This results in complete removal of tert-butanol and of a major part of HDMAP, leaving tubular macropores left by outgoing gases.

The vacuum-dried $\mathrm{ZrO}_{2}-1$ is featuring a dense structure with smooth surfaces of xerogel blocks into which the original crystals of $\mathbf{1}$ have converted. The $\mathrm{ZrO}_{2}-2$ is demonstrating an open macroporous structure with aligned tubular pores, resulting from removal of ligands via hydrolysis-self-assembly-evaporation sequence with appearance much resembling that of hierarchically porous $\mathrm{TiO}_{2}$ obtained from precursors bearing amphiphilic ligands 

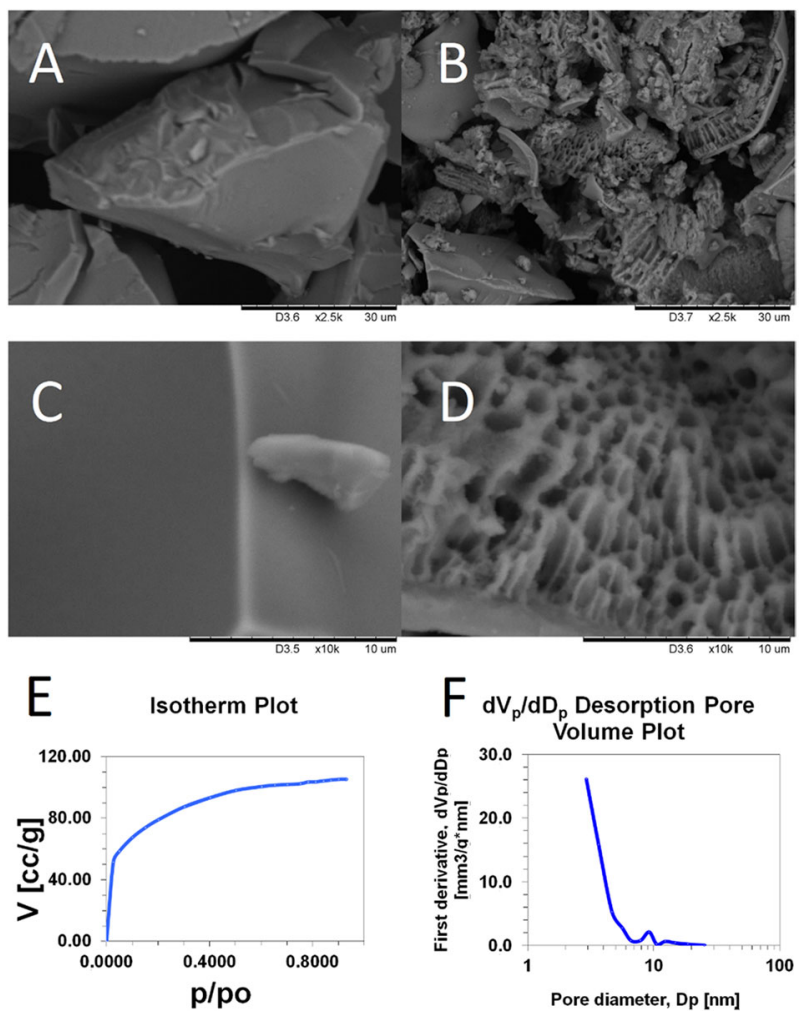

Fig. 5 SEM images of as-prepared $\mathrm{ZrO}_{2}-1$ (a, c) and $\mathrm{ZrO}_{2}-2$ (b, d). $\mathrm{N}_{2}$ adsorption isotherm for $\mathrm{ZrO}_{2}-2$ (e) and pore size distribution (f)

[20]. The BET surface area for $\mathrm{ZrO}_{2}-1$ is less than $1 \mathrm{~m}^{2} / \mathrm{g}$, while for $\mathrm{ZrO}_{2}-2$ it averages about $270 \mathrm{~m}^{2} / \mathrm{g}$ with the micropore volume of about $16 \mathrm{~mm}^{3} / \mathrm{g}$ and micropore area over $40 \mathrm{~m}^{2} / \mathrm{g}$. The apparent size of macropores as observed by SEM is about $1-1.5 \mu \mathrm{m}$. The adsorption isotherm features clearly the Type 1 appearance according to IUPAC classification, typical of systems dominated by micropores [22].

The overall morphology and appearance of materials do not change appreciably with temperature treatment (Fig. 6), while the fine structure is undergoing a clear evolution with collapse of microporosity that culminates at $600{ }^{\circ} \mathrm{C}$, where the microporosity is practically completely eliminated and only (rather uniform) mesoporosity is displayed along with macroporosity. The changes in morphology at the nanometer level are clearly traceable by AFM, featuring denser, larger, and more closely packed blocks, composed apparently of even smaller primary particles. The surface area in total drops to only ca. $40 \mathrm{~m}^{2} / \mathrm{g}$ with sharp domination of mesopores about $3 \mathrm{~nm}$ in diameter. The adsorption isotherm features for this material the Type 4 according to IUPAC classification [22] in agreement with other observations. This transformation is quite logical in the view of densification of the primary particles as a result of heat treatment. Further heat treatment at $900{ }^{\circ} \mathrm{C}$ is associated with increased diffusion of both cations and anions in the $\mathrm{ZrO}_{2}$ structure
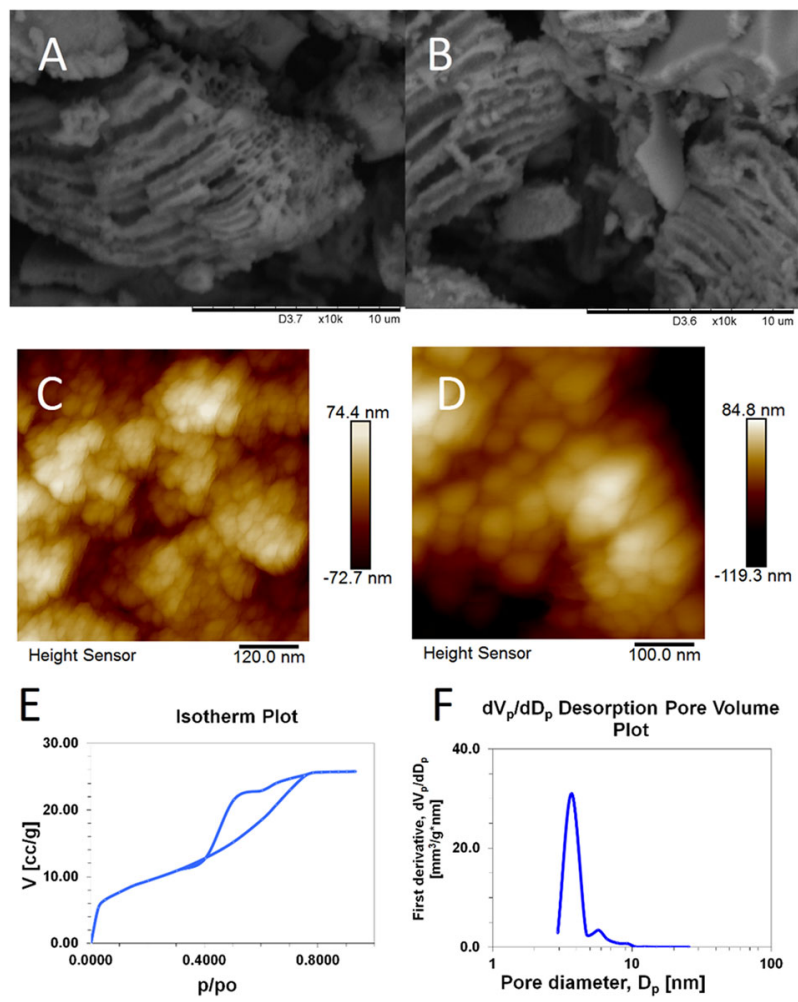

Fig. 6 Morphology of $\mathrm{ZrO}_{2}-2$ samples heat treated at $600{ }^{\circ} \mathrm{C}$ (a) and $900{ }^{\circ} \mathrm{C}$ (b) by SEM. Evolution of the building blocks from $\mathrm{ZrO}_{2}-2$ heat treated at $200{ }^{\circ} \mathrm{C}$ (c) to $\mathrm{ZrO}_{2}-2$ heat treated at $600{ }^{\circ} \mathrm{C}$ (d) samples. $\mathrm{N}_{2}$ adsorption isotherm (e) and pore size distribution (f) for $\mathrm{ZrO}_{2}-2$ after treatment at $600{ }^{\circ} \mathrm{C}$

and causes coalescence of the primary particles with formation of a dense material.

The evolution of the phase composition occurs in parallel with the thermal treatment in the same way for both $\mathrm{ZrO}_{2}-1$ and $\mathrm{ZrO}_{2}-2$ : the materials remain largely $\mathrm{X}$-ray amorphous with patterns looking as coalesced profiles of monoclinic $\mathrm{ZrO}_{2}$ until $600{ }^{\circ} \mathrm{C}$ when the structure sharply transforms into a tetragonal $\mathrm{ZrO}_{2}$ phase [24]. The formation of metastable, higher-symmetry phases at a relatively low temperature is quite common for alkoxide-derived zirconia [25]. The reason for this inversion in stability is most probably doping of the structure with smaller anions, carbon, and especially nitrogen. Further heating of the materials leads to well-defined monoclinic structures, analogous to the mineral baddeleyite [23] (see Fig. 7).

\section{Conclusions}

Aminoalkoxide derivatives of $\mathrm{Zr}$ tert-butoxide feature dimeric cores with heteroligands displaying both chelatingand-bridging function. Microhydrolysis does not lead to detachment of heteroligands and, on the opposite, enhances their binding to the core of the primary particles. Rapid 

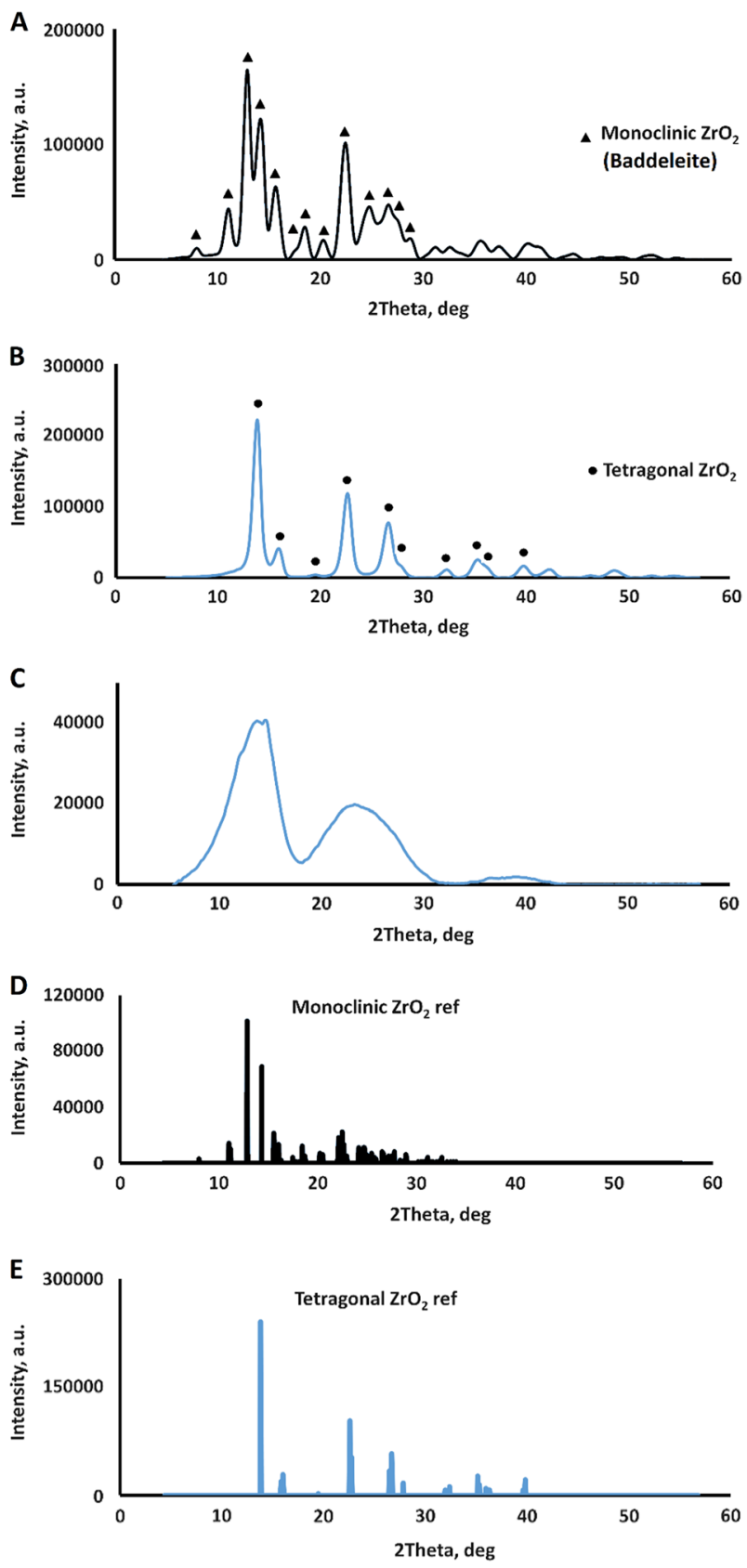

Fig. 7 XRD patterns of $\mathrm{ZrO}_{2}-2$ heat treated at $900{ }^{\circ} \mathrm{C}\left(\right.$ a), $600{ }^{\circ} \mathrm{C}(\mathbf{b})$, and $200{ }^{\circ} \mathrm{C}$ (c) in comparison with reference patterns of monoclinic [23] (d) and tetragonal [24] $\mathrm{ZrO}_{2}$ (e)

hydrothermal treatment of the mixed-ligand precursor opens the possibility to easily produce a material with hierarchical porosity with micro-, meso-, and macroporous structure. The technique is rather simple and robust permitting easy upscaling. Annealing of the hierarchical structure leads to quenching of first micro- and then mesoporosity. The phase transformations for obtained materials follow the common pathway of alkoxide-derived zirconia: first, the mesoporous structure of tetragonal $\mathrm{ZrO}_{2}$ is stabilized at lower temperature supposedly due to doping with carbon and nitrogen atoms. At higher temperature, the pores are lost through annealing and the crystal structure transforms from tetragonal to monoclinic.

Acknowledgements The authors express their gratitude to the Senthech AG Company, Germany, for financial support of this work. The aid from Dr. Denis Kuznetsov in ESI-MS studies of the produced precursors is gratefully acknowledged.

\section{Compliance with ethical standards}

Conflict of interest The authors declare that they have no conflict of interest.

Open Access This article is distributed under the terms of the Creative Commons Attribution 4.0 International License (http://crea tivecommons.org/licenses/by/4.0/), which permits use, duplication, adaptation, distribution, and reproduction in any medium or format, as long as you give appropriate credit to the original author(s) and the source, provide a link to the Creative Commons license, and indicate if changes were made.

\section{References}

1. Leib EW, Vainio U, Pasquarelli RM, Kus J, Czaschke C, Walter N, Janssen R, Müller M, Schreyer A, Weller H, Vossmeyer T (2015) J Colloid Interface Sci 448:582-592

2. Rosengrena $\AA$, Pavlovic E, Oscarsson S, Krajewski A, Ravagliol A, Piancastelli A (2002) Biomaterials 23:1237-1247

3. Lorenz B, Marme S, Muller WEG, Unger K, Schroder HC (1994) Anal Biochem 216:118-126

4. Nawrocki J, Rigney M, McCormick A, Carr PW (1993) J Chromatogr A 657:229-282

5. Zhou H, Li F, He B, Wang J, SUN BD (2007) Trans Nonferrous Metal Sci China 17:389-393

6. Mauer G, Jarligo M, Mack D, Vassen R (2013) J Therm Spray Tech 22:646-658

7. Kreiter R, Rietkerk MDA, Bonekamp BC, van Veen HM, Kessler VG, Vente JF (2008) J Sol-Gel Sci Technol 48:203-211

8. Cao FM, Gao YF,B, Chen HF, Liu XL, Tang XP, Luo HJ (2013) J Solid State Chem 202:168-172

9. Liu YC, Chen JG, Fang KG, Wang YL, Sun YH (2007) Catal Commun 8:945-949

10. Kessler VG, Spijksma GI, Seisenbaeva GA, Håkansson S, Blank DHA, Bouwmeester HJM (2006) J Sol-Gel Sci Technol 40:163179

11. Seisenbaeva GA, Kessler VG (2014) Nanoscale 6:6229-6244

12. Cheng K, Chhor K, Kanaev A (2017) Chem Phys Lett 672:119123

13. Cheng K, Chhor K, Brinza O, Vrel D, Kanaev A (2017) CrystEngComm 19:3955-3965

14. Seisenbaeva GA, Daniel G, Nedelec JM, Gun'ko YK, Kessler VG (2012) J Mater Chem 22:20374-20380

15. Chalkia V, Marathoniti E, Stathopoulos VN (2017) Ceram Int 43:17238-17242

16. Pucci A, Willinger MG, Liu F, Zeng XB, Rebuttini V, Clavel G, Bai X, Ungar G, Pinna N (2012) ACS Nano 6:4382-4391

17. Seisenbaeva GA, Daniel G, Kessler VG, Nedelec JM (2014) Chem Eur J 20:10732-10736

18. Spijksma GI, Huiskes C, Benes NE, Kruidhof H, Blank DHA, Kessler VG, Bouwmeester HJM (2006) Adv Mater 18:2165-2168 
19. Fleeting KA, O'Brien P, Jones AC, Otway DJ, White AJP, Williams DJ (1999) Dalton Trans 1999:2853-2859

20. Seisenbaeva GA, Moloney MP, Tekoriute R, Hardy-Dessources A, Nedelec JM, Gun'ko YK, Kessler VG (2010) Langmuir 26:9809-9817

21. Spijksma GI, Seisenbaeva GA, Bouwmeester HJM, Blank DHA, Kessler VG (2013) Polyhedron 53:150-156
22. Alothman ZA (2012) Materials 5:2874-2902

23. XPD for monoclinic $\mathrm{ZrO}_{2}$, PC-PDF [00-037-1484].

24. 2. XPD for tetragonal $\mathrm{ZrO}_{2}$, PC-PDF [00-050-1089].

25. Mazdiyasni KS, Lynch CT, Smith JS (1966) J Am Ceram Soc 49:286-287 